\title{
Clinicopathological characteristics of breast cancer patients from Northern Tanzania: common aspects of late stage presentation and triple negative breast cancer
} \author{
Alex Mremi ${ }^{4}$, Kondo Chilonga ${ }^{1,2}$, David Msuya ${ }^{1,2}$ and Samuel G Chugulu ${ }^{1,2}$ \\ ${ }^{1}$ Department of General Surgery, Kilimanjaro Christian Medical Centre, PO Box 3010, Moshi, Tanzania \\ ${ }^{2}$ Faculty of Medicine, Kilimanjaro Christian Medical University College, PO Box 2240, Moshi, Tanzania \\ ${ }^{3}$ Cancer Care Centre, Kilimanjaro Christian Medical Centre, PO Box 3010, Moshi, Tanzania \\ ${ }^{4}$ Department of Pathology, Kilimanjaro Christian Medical Centre, PO Box 3010, Moshi, Tanzania
}

Marianne Gnanamuttupulle ${ }^{1,2}$, Oliver Henke ${ }^{3}$ iD, Shilanaiman Hilary Ntundu ${ }^{1,2}$, Furaha Serventi ${ }^{3}$, Leila E Mwakipunda ${ }^{3}$, Patrick Amsi ${ }^{4}$,

\section{Abstract}

Purpose: Breast cancer (BC) is the second most common cancer among Tanzanian women. Oestrogen (ER), progesterone and human epidermal growth factor receptor 2 play major roles in prognosis and treatment but data for Tanzania are sparse. This study aimed to determine these patterns and histological types, tumour grading and staging of BC patients in northern Tanzania for a better understanding of BC in the Sub-Saharan African (SSA) setting.

Methods: A cross-sectional study recorded newly diagnosed BC cases at Kilimanjaro Christian Medical Centre between October 2018 and March 2019. Receptor status, histological types and grade, clinical stage and socio-demographic were recorded and descriptive and bivariate analyses performed.

Results: 116 patients were enrolled. Median age was 53 years, $71.6 \%$ were $\geq 45$ years. The commonest molecular subtype was triple negative breast cancer (TNBC) $(n=33$; 28.4\%). One hundred and two (87.9\%) patients had invasive ductal carcinoma (IDC), poorly differentiated tumours $(60 ; 51.7 \%)$ and clinical stage III disease (62; 53.0\%). ER negative tumours were associated with poorly differentiated histological grade (relative risk (RR): 1.34 (0.87-2.07)), tumour size > $5 \mathrm{~cm}$ (RR: 1.67 (0.33-8.35)) and IDC (RR: 3.35 (0.56-20.23)). Clinical stages III \& IV (odds ratio (OR): $1.64(0.63-4.24))$ were associated with hormone receptor (HR) negative tumours and metastasis (OR: 1.60 (0.68-3.74)) with TNBC. $18 \%$ of the patients reported about first-degree relatives with BC.

Conclusions: Most patients presented in advanced stages and TNBC in their menopause. HR negative tumours were associated with poor histological differentiation and IDC. The high percentage of positive family history of $\mathrm{BC}$ and the differences in receptor patterns compared to other parts of the world should urge further genetic research on BC in SSA.

Keywords: immunohistochemistry patterns, staging, breast cancer, Tanzania, Africa

Correspondence to: Oliver Henke Email: oliver.henke@ukbonn.de

ecancer 2021, 15:1282

https://doi.org/10.3332/ecancer.2021.1282

Published: 07/09/2021

Received: 20/04/2021

Publication costs for this article were supported by ecancer (UK Charity number 1176307).

Copyright: $($ the authors; licensee ecancermedicalscience. This is an Open Access article distributed under the terms of the Creative Commons Attribution License (http:// creativecommons.org/licenses/by/4.0), which permits unrestricted use, distribution, and reproduction in any medium, provided the original work is properly cited. 


\section{Background}

The rising cancer burden among men and women has accounted to 18.1 million new cases and 9.6 million cancer related deaths in the year 2018 [1]. Globally, one in six women develops cancer in their life time and one out of 11 women die from the disease [1]. Breast cancer $(\mathrm{BC})$ is the leading cancer type, in both incidence and mortality among women worldwide [1]. Among 8.6 million newly diagnosed cancers in women, BC accounted for 2.1 million (24.2\%) and among 4.2 million cancer related deaths in women, BC caused 630,000 (15.0\%) in 2018 [1]. Globally, a striking disparity in survival rates is observed among women with BC: Higher survival rates are seen among women in developed countries in contrast to the developing countries [2]. Within Africa, North African women had a higher BC incidence $(29.3 / 100,000)$ than Sub-Saharan African (SSA) women $(22.4 / 100,000)$ [3]. Africa and Asia have higher proportions of cancer related mortality $(7.3 \%$ and $57.3 \%)$ than incidence $(5.8 \%$ and $48.4 \%$ ) and is attributed by higher frequencies of cancers associated with poorer prognosis, with limited access to health care, and late-stage presentation in many countries in these regions [1]. In Tanzania, with respect to estimates from the Global Cancer Observatory (GLOBOCAN) in 2018, cancer incidence in women was 25,028 of which 3,037 (12.1\%) attributed to BC while the cancer mortality in women was 16,501 with 1,303 (7.9\%) deaths from BC [4]. A projected $82 \%$ increase in BC incidence by 2030 has been predicted in Tanzania [5] due to changes in reproductive factors, implementation of screening programmes for prevention and early detection and improvement in health facilities [6].

Characterisation and classification of BC hormone receptor (HR) status oestrogen (ER), progesterone (PR) and human epidermal growth factor receptor 2 (HER2) are of utmost importance to determine the type of treatment and prognosis. These biomarkers in BC have been widely studied and documented in developed countries. In SSA, the patterns of these receptors are not well understood and studies reported from different countries in SSA show wide variations [7]. Triple negative breast cancer (TNBC) was the most common molecular subtype among west and central African patients [8], while hormonal receptor positive tumours were common in east African countries [9]. Eng et al [10] reported a wide range (40\%-80\%) of ER positive BC in North African women and a range of $20 \%-70 \%$ of ER positivity West African women, which points to a wider variation among indigenous Africans. Moreover, studies report that BC in SSA and African Americans is more aggressive than in Caucasians and African patients present with a higher clinical stage and younger age as well as hormonal receptor negative disease [8, 11-15]. Given the geographical diversity of the molecular subtypes of $B C$ in the African continent, these studies cannot generalise a higher aggressiveness of $\mathrm{BC}$ between the African populations and their Caucasian counterparts.

In Tanzania, few data about receptor status in BC patients exist and they have been published from two sites in the western and eastern regions of Tanzania. This study aimed to close the knowledge gap by focusing on the population of the north-east region. We determined receptor patterns, histopathological types, grade and clinical stage of BC in women attending Kilimanjaro Christian Medical Centre (KCMC), the referral and zonal hospital of north-eastern Tanzania.

\section{Methods}

\section{Study design and setting}

A cross-sectional study was performed from beginning of October 2018 to end of March 2019 at KCMC. This hospital has a capacity of 500 beds and belongs to the four consultant hospitals in the country. Its catchment hosts a population of approximately 12 million people and extends into parts of the neighbouring country Kenya. The hospital has a general surgery department with a capacity of 35 beds. The department has four consultants in general surgery, the pathology department has two pathologists and the cancer care centre (oncology department) is managed by two oncologists. This cancer care centre provides chemotherapy services and patients are referred to the National Cancer Institute in the commercial city (Dar-es-Salaam) for radiation services.

\section{Study participants}

All female patients confirmed to have BC by histopathological diagnosis at the pathology department following routine processing who selfpresented or were referred to the General Surgery department (in- and out-patient) during the study period were included. 
Patients with $\mathrm{BC}$ diagnosed from cytological smears only, patients with metastatic cancer from other sites to the breast, male patients and patients who had their biopsy procedures in other health facilities were excluded.

Demographic and clinicopathological characteristics of patients were recorded from the medical records. Tumour grade was assessed by using Nottingham Combined Histologic Grade [16]. Assessment of tumour size, nodal involvement and metastasis status was based on TNM classification [17]. HR status ER, PR and HER2 expressions were determined using standard immunohistochemistry (IHC) protocol.

\section{Ethical considerations}

Ethical approval was granted by Research Ethical Committee of Kilimanjaro Christian Medical University College of Tumaini University. The standards of good clinical practice and good research practice have been maintained according to the Helsinki declaration.

\section{Formalin fixed paraffin embedded block preparation}

All specimens were obtained through an incision or core needle biopsy and immediately fixed in 10\% buffered formalin in less than 5 minutes. These breast tissue blocks which were confirmed by routine haematoxylin and eosin staining for primary histological diagnosis of invasive $\mathrm{BC}$ were taken for IHC staining.

The formalin-fixed, paraffin-embedded breast tumour blocks were cut into $3 \mu \mathrm{m}$ thick sections for each block and then deparaffinised by placing them on a $60^{\circ} \mathrm{C}$ hot plate for $15-30$ minutes. Xylene (two changers) was used to dewax and rehydration was done using alcohol grades of $100 \%, 90 \%$ and $70 \%$, respectively. Antigen retrieval was performed by using a pressure cooker for 40 minutes. Then the slides were cooled by using cold distilled water followed by placing the slides in a citrate buffer for 5 minutes. Tris Buffered Saline was used to wash the slides and then the endogenous activity was blocked using $3 \%$ hydrogen peroxide in Phosphate Buffered Saline. The primary antibodies (ER (clone EP1) and ready to use dilution; PR (clone 636) and ready to use dilution; HER2 protein (clone HercepTest) and ready to use dilution)) provided by DAKO supplies Ltd. were used and incubated for 30 minutes and were followed by Horseradish peroxidase secondary antibody. Finally, diaminobenzidine was used to visualise the staining and the slides were counter stained with haematoxylin.

\section{Immunohistochemistry}

Preparation and fixation of the samples were performed as per the American Society of Clinical Oncology/College of American Pathologists (ASCO/CAP) guidelines [18]. Receptor testing of ER, PR, HER2, tumour grade and histological types was analysed before initiation of chemotherapy and fixed within 24 hours to minimise antigen degradation. Tissue sections of $3 \mu \mathrm{m}$ were H\&E stained, checked for fixation quality and invasive cell adequacy. Immunostaining for ER, PR and HER2 was performed manually.

HER2 receptor staining intensity was determined by the protein expression on tumour cell membrane and scored as $0,1+, 2+$ and $3+($ ASCO/ CAP, HER2 Guidelines, 2018), and $\leq 1+$ was considered HER2 negative, 2+ was considered HER2 equivocal and 3+ was considered HER2 positive [19]. Fluorescent in situ hybridisation (FISH) was not performed for HER2 equivocal 2+ results because of unavailability. Therefore, HER2 equivocal results in this study were considered as positive.

ER and PR were considered positive if $\geq 1 \%$ nuclei of tumour cells were stained according to ASCO/CAP guidelines [20].

BC molecular subtypes were determined using the IHC markers as follows: Luminal A (positive ER and/or PR with negative HER2), Luminal $B$ (positive ER and/or PR with positive HER2), HER2 enriched (negative ER and PR with positive HER2) and triple negative (TNBC) (ER, PR and HER2 negative) [21].

\section{Data analysis}

Statistical data analysis was performed using SPSS software version 25.0 (IBM SPSS statistics for Windows NY; IBM Corp). For categorical variables, data were summarised in proportions and frequency tables. For continuous variables, median and inter-quartile range (IQR) were 
used to summarise data. The $p$-values for categorical variables were calculated for IHC subtypes and demographic and clinical variables using chi-square $\left(X^{2}\right)$. Logistic regression was used to determine odds ratio (OR) and relative risk (RR).

\section{Results}

Final analysis included 116 patients and 28 patients were excluded (6 male patients, 13 biopsies were not obtained at KCMC and in 9 patients, no immunostaining was performed due to logistic constraints).

Table 1 displays the demographics of all participants as well as the clinical characteristics.

Sixty-two (53.4\%) patients were negative for ER and 88 (75.9\%) patients were negative for PR. $44 \%$ of patients were HER2 negative $(0$ and $1+)$ and the same number of patients was HER2 positive (3+). Equivocal results were seen in $14(12 \%)$ patients (2+). Among the concordant 84 (72.4\%) and discordant 32 (27.5\%) patients, hormonal receptor positive and negative tumours were 57 (49.1\%) and 59 (50.9\%), respectively. The molecular subtype categorisation was as follows: TNBC 33 (28.4\%), Luminal B 30 (25.9\%), Luminal A 28 (24.1\%) and HER2 enriched 25 (21.6\%) (Table 2).

\section{Molecular subtype by age group at diagnosis}

Thirty-three (28.4\%) patients were below 45 years and $83(71.6 \%)$ patients were 45 years and above at the time of diagnosis. The majority of the patients below 45 years were diagnosed with Luminal B molecular subtype $(n=13 ; 39.4 \%)$ patients each, while TNBC and Luminal A were the commonest molecular subtype in patients who were $\geq 45$ years $(n=24 ; 28.9 \%$ ). The least common subtype seen in patients aged $<45$ years was Luminal A ( $n=4 ; 12.1 \%$ ) patients, while Luminal B tumours were the least common subtype in patients $\geq 45$ years $(n=17$; $20.5 \%)$. HER2 enriched tumours were equally balanced in both groups with 7 patients $(21.2 \%)$ in the younger and 18 patients ( $21.7 \%)$ in the older group (Figure 1).

\section{Association of clinicopathological parameters with HR negative and TNBC}

Both variables 'clinical stage III/IV' and 'tumour size $>5 \mathrm{~cm}$ ' were associated with higher odds of being ER and PR negative tumours (see Table 3) while the presence of distant metastasis had two times higher odds of TNBC. None of these correlations reached statistically significant levels (Table 3).

Binomial logistic regression analysis for the RR ratio of ER negative BC; stratified by age, tumour size, histological grade, lymph node involvement (LNI) and histological type

On binomial logistic regression, poorly differentiated histological grade tumours had 1.3 times higher risk of being ER negative tumours (RR (95\% Cl): 1.34 (0.87-2.07), $p=0.19$ ) while invasive ductal carcinoma (IDC) had three times higher risk of being ER negative tumours (RR (95\% Cl): 3.35 (0.56-20.23), $p=0.19)$. Tumours > $5 \mathrm{cms}$ in size had two times higher risk of being ER negative tumours (RR (95\% Cl): 1.67 (0.33-8.35), $p=0.53$ ] (Table 4).

\section{Binomial logistic regression analysis for RR ratio of ER and PR negative and TNBC stratified by age, tumour size, histological grade, LNI and histological type}

Poorly differentiated histological grade tumours had 1.4 times higher risk of being ER and PR negative tumours while IDC had three times higher risk of being ER and PR negative tumours. Tumours more than $5 \mathrm{cms}$ in size had two times higher risk of being ER and PR negative tumours. Furthermore, poorly differentiated tumours had two times higher risk of being TNBC and IDC had a two times higher risk of being TNBC (Table 5). 
Table 1. Socio-demographic and clinical characteristics of participants $(N=116)$.

\begin{tabular}{|c|c|c|}
\hline Variables & $n$ & $\%$ \\
\hline Age years (Median, IQR) & $53(43-65)$ & \\
\hline \multicolumn{3}{|l|}{ Age group (years) } \\
\hline$<45$ & 33 & 28.4 \\
\hline$\geq 45$ & 83 & 71.6 \\
\hline \multicolumn{3}{|l|}{ Marital status } \\
\hline Married & 89 & 76.7 \\
\hline Single & 15 & 12.9 \\
\hline Divorce & 5 & 4.3 \\
\hline Widow & 7 & 6.1 \\
\hline \multicolumn{3}{|l|}{ Level of education } \\
\hline Primary & 61 & 52.6 \\
\hline Secondary & 12 & 10.3 \\
\hline Higher & 32 & 27.6 \\
\hline No education & 11 & 9.5 \\
\hline \multicolumn{3}{|l|}{ Residence } \\
\hline Rural & 96 & 82.7 \\
\hline Urban & 20 & 17.3 \\
\hline \multicolumn{3}{|l|}{ Occupation } \\
\hline Farmer & 53 & 45.7 \\
\hline Small-scale business & 32 & 27.6 \\
\hline Professional & 27 & 23.3 \\
\hline Housewife & 4 & 3.4 \\
\hline \multicolumn{3}{|l|}{ Insurance coverage } \\
\hline Yes & 76 & 65.5 \\
\hline No & 40 & 34.5 \\
\hline \multicolumn{3}{|l|}{ Alcohol intake } \\
\hline Yes & 78 & 67.2 \\
\hline No & 38 & 32.8 \\
\hline \multicolumn{3}{|c|}{ History of cancer in the family } \\
\hline History of BC & 27 & 23.3 \\
\hline First degree & 21 & 18.1 \\
\hline Second degree & 6 & 5.2 \\
\hline No history of BC & 56 & 48.3 \\
\hline Unknown & 33 & 28.4 \\
\hline History of cervical cancer & 5 & 4.3 \\
\hline \multicolumn{3}{|l|}{ Menopausal status } \\
\hline Premenopausal & 37 & 31.9 \\
\hline
\end{tabular}


Table 1. Continued

\begin{tabular}{|c|c|c|}
\hline Postmenopausal & 79 & 68.1 \\
\hline \multicolumn{3}{|l|}{ Contraceptive use } \\
\hline Yes & 78 & 67.2 \\
\hline No & 38 & 32.8 \\
\hline \multicolumn{3}{|l|}{ Type of contraceptives $(n=78)$} \\
\hline Hormonal contraceptives & 71 & 91.0 \\
\hline Other contraceptives & 7 & 9.0 \\
\hline \multicolumn{3}{|l|}{ Parity } \\
\hline Nulliparous & 6 & 5.2 \\
\hline $1-2$ & 31 & 26.7 \\
\hline$\geq 3$ & 79 & 68.1 \\
\hline \multicolumn{3}{|l|}{ Age at pregnancy (years) $(n=110)$} \\
\hline$<20$ & 20 & 18.2 \\
\hline $20-29$ & 87 & 79.1 \\
\hline$\geq 30$ & 3 & 2.7 \\
\hline \multicolumn{3}{|l|}{ Tumour size (cms) } \\
\hline$<2$ & 3 & 2.6 \\
\hline $2-5$ & 32 & 27.6 \\
\hline$>5$ & 81 & 69.8 \\
\hline \multicolumn{3}{|l|}{ LNI } \\
\hline Absent & 27 & 23.3 \\
\hline Present & 89 & 76.7 \\
\hline \multicolumn{3}{|l|}{ Distant metastasis } \\
\hline Absent & 79 & 68.1 \\
\hline Present & 37 & 31.9 \\
\hline \multicolumn{3}{|l|}{ Site of metastasis $(n=37)$} \\
\hline Lung & 16 & 43.2 \\
\hline Spine & 9 & 24.3 \\
\hline Both lung and spine & 4 & 10.8 \\
\hline $\begin{array}{l}\text { Others (liver, brain \& contralateral } \\
\text { breast) }\end{array}$ & 8 & 21.6 \\
\hline
\end{tabular}

\section{Histological types and grade}

One hundred and two (87.9\%) patients were diagnosed with IDC and 6 (5.2\%) patients had invasive lobular carcinoma (ILC). Poorly differentiated tumours were common in 60 (51.7\%) patients compared to well differentiated tumours in $13(11.2 \%)$ patients.

\section{Clinical stage}

Sixty-two (53.0\%) patients were diagnosed in stage III, 32 (28.0\%) in stage IV, 20 (17.0\%) in stage II and only 2 (2.0\%) patients in stage I. 
Table 2. Proportions of BC hormone (ER \& PR) and HER2 receptors $(n=116)$.

\begin{tabular}{|l|l|c|c|}
\hline \multicolumn{1}{|c|}{ Hormonal receptor status } & \multicolumn{1}{c|}{ Status } & $\boldsymbol{n}$ & $\%$ \\
\hline ER & Positive & 54 & 46.6 \\
\hline & Negative & 62 & 53.4 \\
\hline PR & Positive & 28 & 24.1 \\
\hline HER2 & Negative & 88 & 75.9 \\
\hline & Positive (3+) & 51 & 44.0 \\
\hline & Negative (0 and 1+) & 51 & 44.0 \\
\hline Concordant and discordant & Equivocal (2+) & 14 & 12.0 \\
\hline aConcordant ( $=\mathbf{8 4})$ & & & \\
\hline & ER+PR+ & 25 & 29.8 \\
\hline bDiscordant ( $\boldsymbol{n}=32$ ) & ER-PR- & 59 & 70.2 \\
\hline & ER+PR- & 29 & 90.6 \\
\hline Hormonal receptor positive tumours & ER+PR+ & 3 & 9.4 \\
\hline Hormonal receptor negative tumours & ER-PR- & 57 & 49.1 \\
\hline Molecular subtype & Luminal A & 59 & 50.9 \\
\hline & Luminal B & 28 & 24.1 \\
\hline & HER2-enriched & 25 & 21.6 \\
\hline & Triple negative & 33 & 28.4 \\
\hline
\end{tabular}

aBoth ER and PR either positive or negative

${ }^{\mathrm{b}} \mathrm{ER}$ is positive or negative and $\mathrm{PR}$ is negative or positive, respectively

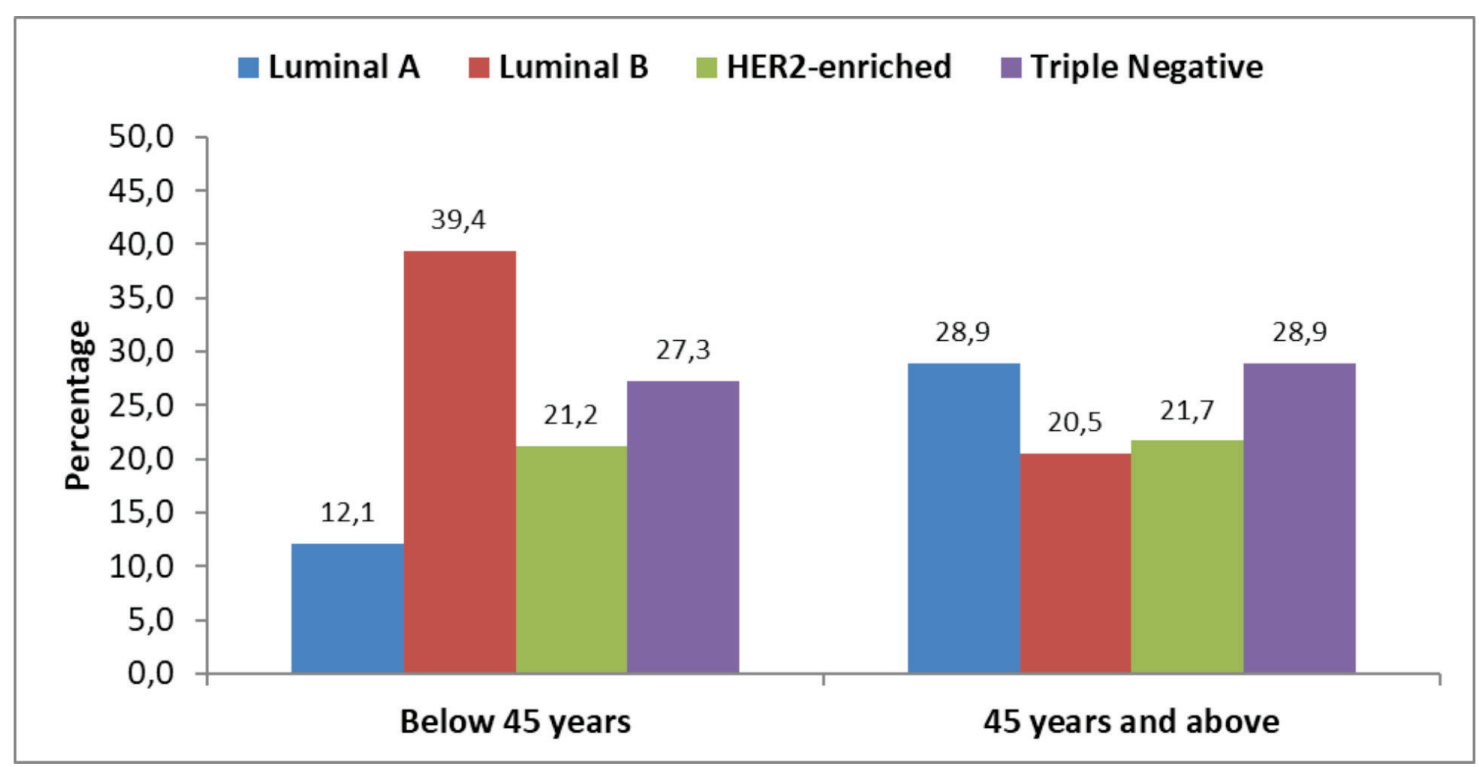

Figure 1. Molecular subtypes by age at diagnosis $(n=116)$. 
Table 3. Association of clinicopathological parameters with HR negative and TNBC in study participants $(n=116)$.

\begin{tabular}{|c|c|c|c|c|c|c|c|}
\hline \multirow{3}{*}{$\begin{array}{l}\text { Clinical and } \\
\text { pathological tumour } \\
\text { characteristics }\end{array}$} & \multirow[t]{3}{*}{$N$} & \multicolumn{6}{|c|}{ Statistical estimate for the hormonal receptor status } \\
\hline & & \multicolumn{3}{|c|}{ ER \& PR negative } & \multicolumn{3}{|c|}{ Triple negative } \\
\hline & & $n(\%)$ & OR $(95 \% \mathrm{Cl})$ & $p$-value & $n(\%)$ & OR $(95 \% \mathrm{Cl})$ & $p$-value \\
\hline \multicolumn{8}{|l|}{ Age (years) } \\
\hline$<45$ & 33 & $16(48.5)$ & $0.88(0.39-1.97)$ & 0.75 & $9(27.3)$ & $0.92(0.37-2.28)$ & 0.86 \\
\hline$\geq 45$ & 83 & $43(51.8)$ & ref & & $24(28.9)$ & ref & \\
\hline \multicolumn{8}{|l|}{ Tumour size $(\mathrm{cm})$} \\
\hline$<2$ & 3 & $1(33.3)$ & ref & & $1(33.3)$ & ref & \\
\hline $2-5$ & 32 & $14(43.8)$ & $1.56(0.12-19.74)$ & 0.73 & $7(21.9)$ & $0.56(0.04-7.44)$ & 0.66 \\
\hline$>5$ & 81 & $44(54.3)$ & $2.38(0.20-27.90)$ & 0.48 & $25(30.9)$ & $0.89(0.08-10.46)$ & 0.93 \\
\hline \multicolumn{8}{|l|}{ Histological grade } \\
\hline Poorly & 60 & $30(50.0)$ & $0.44(0.12-1.64)$ & 0.21 & $14(23.3)$ & $0.36(0.10-1.27)$ & 0.10 \\
\hline Moderately & 43 & $20(46.5)$ & $0.39(0.10-1.51)$ & 0.15 & $13(30.2)$ & $0.51(0.14-1.84)$ & 0.29 \\
\hline Well & 13 & $9(69.2)$ & ref & & $6(46.2)$ & ref & \\
\hline \multicolumn{8}{|l|}{ LNI } \\
\hline Absent & 27 & $12(44.4)$ & ref & & $9(33.3)$ & ref & \\
\hline Present & 89 & $47(52.8)$ & $1.40(0.59-3.34)$ & 0.44 & $24(27.0)$ & $0.74(0.29-1.88)$ & 0.52 \\
\hline \multicolumn{8}{|l|}{ Metastasis } \\
\hline Absent & 79 & $40(50.6)$ & ref & & $20(25.3)$ & ref & \\
\hline Present & 37 & $19(51.4)$ & $1.03(0.47-2.26)$ & 0.94 & $13(35.1)$ & $1.60(0.68-3.74)$ & 0.28 \\
\hline \multicolumn{8}{|l|}{ Clinical stage } \\
\hline Early (I \& II) & 22 & 9 (40.9) & ref & & $6(27.3)$ & ref & \\
\hline Late (III \& IV) & 94 & $50(53.2)$ & $1.64(0.63-4.24)$ & 0.30 & 27 (28.7) & $1.08(0.38-3.05)$ & 0.89 \\
\hline
\end{tabular}

LNI, Lymph node involvement

Table 4. Binomial logistic regression analysis for RR ratio of ER negative BC stratified by age, tumour size, histological grade, $\mathrm{LNI}$ and histological type $(n=116)$.

\begin{tabular}{|l|l|c|c|c|}
\hline \multicolumn{1}{|c|}{ Variable } & \multicolumn{1}{|c|}{ Categories } & Risk ratio & $95 \% \mathrm{Cl}$ & $p$-value \\
\hline Age group (years) & $<45$ & ref & & \\
\hline & $\geq 45$ & 1.14 & $0.77-1.71$ & 0.51 \\
\hline & & & & \\
\hline Tumour size (cms) & $<2$ & ref & & \\
\hline & $2-5$ & 1.5 & $0.29-7.71$ & 0.63 \\
\hline & $>5$ & 1.67 & $0.33-8.35$ & 0.53 \\
\hline & & & & \\
\hline Histological grade & Well differentiated & ref & & \\
\hline
\end{tabular}


Table 4. Continued

\begin{tabular}{|l|l|c|c|c|}
\hline & Moderately differentiated & 0.10 & $0.68-1.45$ & 0.96 \\
\hline & Poorly differentiated & 1.34 & $0.87-2.07$ & 0.19 \\
\hline & & & & \\
\hline LNI & Absent & ref & & \\
\hline & Present & 1.04 & $0.69-1.57$ & 0.85 \\
\hline Histological type & & & & \\
\hline & ILC (NST) & ref & & \\
\hline & IDC & 3.35 & $0.56-20.23$ & 0.19 \\
\hline & Others & 3.00 & $0.44-20.44$ & 0.26 \\
\hline
\end{tabular}

LNI, Lymph node involvement; IDC (NST), Invasive ductal carcinoma (no special type); ILC, Invasive lobular carcinoma

anvasive adenosquamous cell carcinoma, Paget's disease and anaplastic BC

Table 5. Binomial logistic regression analysis for RR ratio of ER and PR negative and TNBC stratified by age, tumour size, histological grade, LNI and histological type $(n=116)$.

\begin{tabular}{|c|c|c|c|c|c|}
\hline Variable & Categories & ER \& PR negative & & TNBC & \\
\hline & & RR (95\% Cl) & $p$-value & $\operatorname{RR}(95 \% \mathrm{Cl})$ & $p$-value \\
\hline \multirow[t]{2}{*}{ Age group (years) } & $<45$ & ref & & & \\
\hline & $\geq 45$ & $1.07(0.71-1.61)$ & 0.75 & $1.06(0.55-2.03)$ & 0.86 \\
\hline \multirow[t]{3}{*}{ Tumour size $(\mathrm{cm})$} & $<2$ & ref & & & \\
\hline & $2-5$ & $1.31(0.25-6.82)$ & 0.75 & $0.66(0.12-3.70)$ & 0.63 \\
\hline & $>5$ & $1.63(0.32-8.17)$ & 0.55 & $0.92(0.18-4.74)$ & 0.93 \\
\hline \multirow[t]{3}{*}{ Histological grade } & Well differentiated & ref & & & \\
\hline & Moderately differentiated & $0.93(0.61-1.40)$ & 0.73 & $1.30(0.68-2.47)$ & 0.43 \\
\hline & Poorly differentiated & $1.38(0.90-2.15)$ & 0.15 & $1.98(0.94-4.17)$ & 0.07 \\
\hline \multirow[t]{2}{*}{ LNI } & Absent & ref & & & \\
\hline & Present & $1.19(0.75-1.90)$ & 0.73 & $0.81(0.43-1.52)$ & 0.51 \\
\hline \multirow[t]{3}{*}{ Histological type } & ILC (NST) & ref & & & \\
\hline & IDC & $3.18(0.53-19.19)$ & 0.21 & $1.76(0.29-10.83)$ & 0.54 \\
\hline & Others $^{a}$ & $3.00(0.44-20.44)$ & 0.26 & $1.50(0.17-12.94)$ & 0.71 \\
\hline
\end{tabular}

LNI, Lymph node involvement; IDC (NST), Invasive ductal carcinoma (no special type); ILC, Invasive lobular carcinoma alnvasive adenosquamous cell carcinoma, Paget's disease and anaplastic BC 


\section{Discussion}

Though several studies on BC have been published in SSA, there are only a few studies conducted in Tanzania and for the northern part of the country almost no data exist. Thus, this study was conducted to address the clinicopathological findings of patients in this region. The major findings in regard to the IHC pattern were that half of the patients had HR positive tumours while TNBC was reported in $28.4 \%$ followed by the HER2 enriched tumours as the least common molecular subtype. The majority of the patients were diagnosed with IDC and half of the patients had poorly differentiated tumours. $81 \%$ of the patients had an advanced stage disease (stage III or IV) at diagnosis.

\section{Age and menopause}

The most commonly affected age group was 45 years and above with a mean age of 53 years. Our findings are similar to the other studies done in Tanzania by Mwakigonja et al [22] and in Nigeria by Adesunkanmi et al [23], who reported the mean age at diagnosis as 49 years and 48 years, respectively. African British women too present with a similar mean age of 46 years [24], but this age was lower than their Caucasian counterparts as revealed in studies done in Europe and America [25, 26].

$B C$ seems to affect younger individuals in Africa and of African descent living in other regions of the world [27, 28]. Therefore, BC poses a higher negative economic burden to affected families in Africa.

Almost $70 \%$ of our patients were postmenopausal, which is conclusive with studies conducted in Europe [29-31] but stands in contrast with a Ugandan study that displayed $69 \%$ of premenopausal women with BC [28]. This shows - again - the differences among the African population but bearing in mind that most of the studies are single centre studies with small number of participants.

\section{Family history}

About one third of the participants reported a history of BC or cervical cancer in the family, and $18.1 \%$ of these patients reported to have a first-degree relative diagnosed to have BC. In a study reported by Ford et al [32], families with BRCA1 and BRCA2 mutations had $28 \%$ and $37 \%$ of women with $\mathrm{BC}$, respectively. As these germ line mutations were not analysed, we cannot draw conclusion on these genetic mutations in our study but the high percentage of familiar BC suggests genetic mutations as common.

\section{Late stage presentation}

Most of our patients had a tumour size at diagnosis of $\geq 5 \mathrm{~cm}$ and only $2.6 \%$ had tumours less than $2 \mathrm{~cm}$. Similar findings were reported by other studies in Tanzania [22, 27] and Nigeria [33]. Studies from India and Italy reported that the majority of their patients had smaller tumours with less than $2 \mathrm{~cm}$ and $2-5 \mathrm{~cm}$ and only few patients presented with bigger tumours [34,35]. Furthermore, almost $80 \%$ had lymph node metastasis at the time of diagnosis, which corresponds to other publications from Tanzania, Kenya and India [9, 27, 34]. A quarter of our participants presented with distant metastasis. In contrast, the 'Carolina BC Study' in the USA found that majority of the patients $61 \%$ did not have distant or lymph node metastasis at the time of diagnosis [36]. This might be a feature of either more aggressive BC and/or late stage presentation in indigenous Africans than in their Caucasian counterparts, driven by poor health knowledge, financial constrains and both limited health facilities and screening programmes [22, 27, 37].

\section{Hormone receptor expression}

In contrast to studies conducted earlier in Kenya [9] and the USA [36] that displayed 71\% and $60 \%$ HR positive patients, our study cohort showed less than $50 \%$ positivity. Several other studies performed on African descendents reported as well lower ER rates but these studies were based mainly on archive samples with the risk of biological degradation of the samples and false negative results. This can be excluded from our study and our findings are in line with another study from Tanzania [22] and from Sudan and Eritrea [15], showing also less than half of the patients HR positive. In conclusion, HR positive among Africans remains highly heterogeneous among different regions, but it can be said to be in general lower than in Caucasians. 
Positive PR expression was lower in our cohort and in a study conducted previously in Tanzania [22]. But again, the previously mentioned studies from Sudan and Eritrea (47.7\%) [15] are also in the PR expression in line with our findings. That stands in stark contrast to findings from Caucasian populations with a generally higher expression [21].

\section{HER2 receptor}

Considering equivocal results as positive, our cohort shows almost half of all participants positive for HER2, while two other studies from Tanzania reported positive HER2 expression on BC to be only 15\% [22] and 26\% [38]. Neither of these studies reported equivocal results. As mentioned earlier, FISH could not be performed, but if it is performed on equivocal results, approximately $21 \%$ of the samples will be interpreted as positive [39]. It is likely that we overestimated the positive HER2 results, but we would still have $44 \%$ positive results, considering equivocal results as negative. Low HER2 positive results were not only found in other Tanzanian studies but also noted in the Eritrean and Sudanese cohort [15] and among British black BC patients [24].

\section{TNBC}

About one third of the patients had TNBC. Other studies reported from regions with African descendents presented similar results; $38.4 \%$ [27], 29.2\% [33] and 36.0\% [40]. Mwakigonja et al [22] reported a higher proportion 45.6\% of patients with TNBC, but with a small sample size of only 46 patients. The 'Carolina BC Study' reported a significant higher prevalence of TNBC (26\%) in African Americans than their nonAfrican American counterparts (16\%) [36] which is conclusive with studies from China, Northern America and India (11.1\% [41], 13.4\% [21] and $16.7 \%$ [42]).

These results on BC HRs demonstrate genetic multiplicity of BC across races and among different groups in indigenous Africans in SSA but bearing in mind the non-representativeness of most of the SSA studies.

In our study on molecular subtypes, the biggest difference between younger and older patients can be found in Luminal A and B. While in the young cohort $<45$ years of age, Luminal B was more prevalent with $40 \%$, it was only found in $29 \%$ in patients aged $\geq 45$ years and Luminal $A$ tumours were correspondingly $10 \%$ lower in the younger group. These differences can be attributed to higher proportions of HER2 positive $\mathrm{BC}$ in our study as discussed above.

\section{Histological grading}

Our patients with ER negative BC and TNBC were more likely to have poorly differentiated histological grade tumours which are in line with previous findings $[7,43]$. This implies that aggressive grades of BC are mostly seen in ER negative and TNBC patients. A previous study under the cooperation of KCMC's pathology department displayed the same result with a higher proportion of high grade tumours compared to white American women with BC [44]. While these findings are associated with shorter survival and distant recurrence of the tumour [45], the aforementioned study also assessed tumour infiltrating lymphocytes (TILs). TILs are known to correlate with a better treatment outcome and prognosis in patients from European ancestry [44] and interestingly, the study revealed higher proportions of TIL involvement in the Tanzanian patients compared to white American BC patients. Stratified to ER negative patients only, the difference was not significant and further studies are needed to understand this correlation and which influence infections and other environmental exposures might have on the anti-tumour immune response [44]. A Japanese study has shown that high TIL grades within the ER negative BC patients predict better relapse-free survival and cancer-specific survival, while it is a poor prognostic marker for ER positive patients [46]. Whether the high ER negative proportion among the Tanzanian BC patients in combination with high TIL grades leads to good therapy outcomes remains to be proofed by prospective studies.

The most common histological type of BC in this study was IDC and was reported in $87.9 \%$ patients. Also, this finding corresponds to studies in Africa and Europe [22, 47]. Majority of patients in a study conducted in the USA reported features of IDC in 72.7\% patients [21]. This indicates that IDC is the most common histological type across many races and regions. 


\section{Clinical staging}

Stage III BC is the most common stage at diagnosis followed by stage IV, together accounted to more than $80 \%$. Similar trend was reported in Uganda by Galukande et al [48], in their study. An opposite trend was reported in a study performed in four European countries and Australia whereby patients with BC in stages I and II were the vast majority [49]. This shows that patients in our region have an advanced disease at the time of diagnosis compared to Caucasian patients or patients from developed regions of the world. It should prompt action on health education and promotion of screening programmes in Northern Tanzania as this has been proven to be effective for earlier presentation of BC patients [50].

Clinical stage III tumours were the majority in all four molecular subtype groups. Majority of patients with HER2-enriched molecular subtype tumours had stage III tumours. A previous study has reported that women with HER2 enriched molecular subtype tumours exhibit $26 \%$ higher risk of mortality within 5 years of diagnosis and higher mortality was associated with the stage at diagnosis and the HER2 receptor status [51]. This demonstrates the aggressiveness of HER2-enriched tumours among our study participants.

\section{Limitations}

FISH was not performed to evaluate HER2+ equivocal results due to unavailability. Also, the proliferative index marker, Ki67 was not performed which could have contributed to a better understanding of the aggressiveness of the tumour. Because of the limited number of participants, the results should be interpreted with caution and cannot be generalised.

\section{Conclusions}

The data presented in this study suggest that BC in Northern Tanzania is more aggressive and is of a higher stage at diagnosis compared to Western countries. In general, most of the data corresponds with other studies from SSA and contributes to the body of evidence about the different biology of $\mathrm{BC}$ in this part of the world. However, the remarkable different results on HR and HER2 demonstrate the genetic multiplicity of BC among different groups in African descendents. Even though interpretation must be done cautiously as most of the studies from SSA are not representative samples of the population, but the heterogeneous results should promote more genetic studies in the future to understand the real world setting in SSA. Enhancing health literacy and expanding prevention programmes should be a focus of health policy makers in Tanzania to reduce the high rate of late presentation in BC.

\section{Declaration}

\section{Ethics approval and consent to participate}

This study was approved by Research Ethical Committee of Kilimanjaro Christian Medical University College of Tumaini University with a certificate No.2354, and permission was granted to access patient's information. Consent to participate was not applicable.

\section{Consent for publication}

Not applicable.

\section{Availability of data and material}

Data will be available upon contacting corresponding author on reasonable request. 


\section{Competing interests}

All authors have no conflicts of interests.

\section{Funding}

There was no specific funding received for this research.

\section{Authors' contributions}

MG: study design, data analysis, interpretation, drafting and critical review of manuscript. DM, FS, PA, AM and KC: critical review of manuscript. LEM: data collection and critical review of manuscript. $\mathrm{OH}$ : statistical analysis, data interpretation, drafting and critical review of manuscript. SHN: study design, statistical analysis, data interpretation, drafting and critical review of manuscript. SGC: supervision, study design, statistical analysis, data interpretation, drafting and critical review of manuscript.

\section{Acknowledgements}

The authors are grateful to Ms. Ummil-Khairat J. Koosa and the staff at the pathology department of KCMC for their assistance in processing the tissue biopsy blocks. The authors also wish to extend their gratitude to Mr. Julius Pius Alloyce for statistical assistance and all the patients and staff in General Surgery department at KCMC.

\section{References}

1. Bray F, Ferlay J, and Soerjomataram I, et al (2018) Global cancer statistics 2018: GLOBOCAN estimates of incidence and mortality worldwide for 36 cancers in 185 countries CA: Cancer J Clin 68(6) 394-424.

2. Ginsburg O, Bray F, and Coleman MP, et al (2017) The global burden of women's cancers: a grand challenge in global health Lancet 389(10071) 847-860 https://doi.org/10.1016/S0140-6736(16)31392-7

3. Adeloye D, Sowunmi OY, and Jacobs W, et al (2018) Estimating the incidence of breast cancer in Africa: a systematic review and metaanalysis J Glob Health 8(1) 010419 https://doi.org/10.7189/jogh.08.010419 PMID: 29740502 PMCID: 5903682

4. Ferlay J, Colombet M, and Soerjomataram I, et al (2019) Estimating the global cancer incidence and mortality in 2018: GLOBOCAN sources and methods Int J Cancer 144(8) 1941-1953 https://doi.org/10.1002/ijc.31937

5. International Agency for Research on Cancer GLOBOCAN, Cancer tomorrow [https://gco.iarc.fr/tomorrow/en/dataviz/trends?types=0 $\underline{\text { \&sexes }=2 \& \text { mode=cancer\&group_populations }=0 \& \text { multiple_populations=0\&multiple_cancers }=1 \& \text { cancers }=20 \_23 \& \text { populations }=910 \& a p}$ $\mathrm{c}=$ cat_ca20v1.5_ca23v-1.5]

6. Torre LA, Islami F, and Siegel RL, et al (2017) Global cancer in women: burden and trends Cancer Epidemiol Biomarkers Prev 26(4) 444-457 https://doi.org/10.1158/1055-9965.EPI-16-0858 PMID: 28223433

7. McCormack VA, Joffe M, and van den Berg E, et al (2013) Breast cancer receptor status and stage at diagnosis in over 1,200 consecutive public hospital patients in Soweto, South Africa: a case series Breast Cancer Res 15(5) R84 https://doi.org/10.1186/bcr3478 PMID: 24041225 PMCID: 3978918

8. Brinton LA, Figueroa JD, and Awuah B, et al (2014) Breast cancer in Sub-Saharan Africa: opportunities for prevention Breast Cancer Research Treat 144(3) 467-478 https://doi.org/10.1007/s10549-014-2868-z 
9. Sayed S, Moloo Z, and Wasike R, et al (2014) Is breast cancer from Sub Saharan Africa truly receptor poor? Prevalence of ER/PR/HER2 in breast cancer from Kenya Breast 23(5) 591-596 https://doi.org/10.1016/j.breast.2014.06.006 PMID: 25012047

10. Eng A, McCormack V, and dos-Santos-Silva I (2014) Receptor-defined subtypes of breast cancer in indigenous populations in Africa: a systematic review and meta-analysis PLoS Med 11(9) e1001720 https://doi.org/10.1371/journal.pmed.1001720 PMID: 25202974 PMCID: 4159229

11. Jiagge E, Jibril AS, and Chitale D et al (2016) Comparative analysis of breast cancer phenotypes in African American, white American, and west versus east African patients: correlation between African ancestry and triple-negative breast cancer Ann Surg Oncol 23(12) 3843-3849 https://doi.org/10.1245/s10434-016-5420-z PMID: 27469125

12. Newman LA, Reis-Filho JS, and Morrow M, et al (2015) The 2014 society of surgical oncology Susan G. Komen for the cure symposium: triple-negative breast cancer Ann Surg Oncol 22(3) 874-882 https://doi.org/10.1245/s10434-014-4279-0

13. Bowen RL, Duffy SW, and Ryan DA, et al (2008) Early onset of breast cancer in a group of British black women Br J Cancer 98(2) 277 https://doi.org/10.1038/sj.bjc.6604174 PMID: 18182985 PMCID: 2361454

14. Gukas ID, Girling AC, and Mandong BM, et al (2008) A comparison of clinicopathological features and molecular markers in British and Nigerian women with breast cancer Clin Med Oncol 2 347-351. PMID: 21892296 PMCID: 3161669

15. Sengal AT, Haj-Mukhtar NS, and ElhajAM, et al (2017) Immunohistochemistry defined subtypes of breast cancer in 678 Sudanese and Eritrean women; hospitals based case series BMC Cancer 17(1) 804 https://doi.org/10.1186/s12885-017-3805-4 PMID: 29191181 PMCID: 5710067

16. Elston CW, and Ellis IO (1991) Pathological prognostic factors in breast cancer. I. The value of histological grade in breast cancer: experience from a large study with long term follow up CW Elston \& IO Ellis. Histopathology 199119 403-410 AUTHOR COMMENTARY Histopathology 2002 Sep41(3a) 151 https://doi.org/10.1111/j.1365-2559.1991.tb00229.x PMID: 1757079

17. Sobin LH, Gospodarowicz MK, and Wittekind C, eds (2011) TNM classification of malignant tumours (New York: John Wiley \& Sons)

18. Hicks DG (2014) Standardization of tissue handling from the OR to the laboratory AORN: Assoc Oper Room Nurs J 99(6) 810 https://doi. org/10.1016/j.aorn.2014.03.005

19. Wolff AC, Hammond ME, and Allison KH, et al (2018) Human epidermal growth factor receptor 2 testing in breast cancer: American Society of Clinical Oncology/College of American Pathologists clinical practice guideline focused update Arch Pathol Lab Med 142(11) 1364-82 https://doi.org/10.5858/arpa.2018-0902-SA PMID: 29846104

20. Hammond ME, Hayes DF, and Dowsett M, et al (2010) American Society of Clinical Oncology/College of American Pathologists guideline recommendations for immunohistochemical testing of estrogen and progesterone receptors in breast cancer (unabridged version) Arch Pathol Lab Med 134(7) e48-e72 https://doi.org/10.5858/134.7.e48 PMID: 20586616

21. Onitilo AA, Engel JM, and Greenlee RT, et al (2009) Breast cancer subtypes based on ER/PR and Her2 expression: comparison of clinicopathologic features and survival Clin Med Res 7(1-2) 4-13 https://doi.org/10.3121/cmr.2008.825 PMID: 19574486 PMCID: 2705275

22. Mwakigonja AR, Lushina NE, and Mwanga A (2017) Characterization of hormonal receptors and human epidermal growth factor receptor-2 in tissues of women with breast cancer at Muhimbili National Hospital, Dar es salaam, Tanzania Infect Agents Cancer 12(1) 60 https://doi.org/10.1186/s13027-017-0170-5

23. Adesunkanmi AR, Lawal OO, and Adelusola KA, et al (2006) The severity, outcome and challenges of breast cancer in Nigeria Breast 15(3) 399-409 https://doi.org/10.1016/j.breast.2005.06.008

24. Bowen RL, Duffy SW, and Ryan DA, et al (2008) Early onset of breast cancer in a group of British black women Br J Cancer 98(2) 277 https://doi.org/10.1038/sj.bjc.6604174 PMID: 18182985 PMCID: 2361454 
25. Abdulrahman GO, and Rahman GA (2012) Epidemiology of breast cancer in Europe and Africa J Cancer Epidemiol 2012915610 https:// doi.org/10.1155/2012/915610 PMID: 22693503 PMCID: 3368191

26. Elmore JG, Moceri VM, and Carter D, et al (1998) Breast carcinoma tumor characteristics in black and white women Cancer: Interdiscip Int J Am Cancer Soc 83(12) 2509-2515 https://doi.org/10.1002/(SICI)1097-0142(19981215)83:12\&lt;2509::AID-CNCR15\&gt;3.0.CO;2-V

27. Rambau P, Masalu N, and Jackson K, et al (2014) Triple negative breast cancer in a poor resource setting in North-Western Tanzania: a preliminary study of 52 patients BMC Res Notes 7(1) 399 https://doi.org/10.1186/1756-0500-7-399 PMID: 24964871 PMCID: 4081017

28. Galukande M, Wabinga H, and Mirembe F, et al (2014) Molecular breast cancer subtypes prevalence in an indigenous Sub Saharan African population Pan Afr Med J 17249 https://doi.org/10.11604/pamj.2014.17.249.3305 PMID: 25309649 PMCID: 4189896

29. Public Health Wales NHS Trust (2010) WCISU Annual Publication No. SA10/01: Cancer Incidence in Wales 2004-2008 (Cardiff: Welsh Cancer Intelligence and Surveillance Unit) [http://www.wales.nhs.uk/sites3/Documents/242/incpub2010 .pdf]

30. Cancer Registry of Norway (2011) Cancer in Norway: Cancer in Norway 2009-Cancer incidence, mortality, survival and prevalence in Norway (Oslo: Cancer Registry of Norway)

31. Finnish Cancer Registry (2011) Cancer stat fact sheets (Helsinki: Institute for Statistical and Epidemiological Cancer Research)

32. Ford D, Easton DF, and Stratton M, et al (1998) Genetic heterogeneity and penetrance analysis of the BRCA1 and BRCA2 genes in breast cancer families Am J Hum Genet 62(3) 676-689 https://doi.org/10.1086/301749 PMID: 9497246 PMCID: 1376944

33. Nwafor CC, and Keshinro SO (2015) Pattern of hormone receptors and human epidermal growth factor receptor 2 status in sub-Saharan breast cancer cases: private practice experience Niger J Clin Pract 18(4) 553-558 https://doi.org/10.4103/1119-3077.156905 PMID: 25966732

34. Bansal C, Sharma A, and Pujani M, et al (2017) Correlation of hormone receptor and human epidermal growth factor Receptor-2/ neu expression in breast cancer with various clinicopathologic factors Indian J Med Paediatr 38(4) 483 https://doi.org/10.4103/ijmpo. ijmpo_98_16

35. Ongaro E, Gerratana L, and Cinausero M, et al (2018) Comparison of primary breast cancer and paired metastases: biomarkers discordance influence on outcome and therapy Future Oncol 14(9) 849-859 https://doi.org/10.2217/fon-2017-0384 PMID: 29527957

36. Carey LA, Perou CM, and Livasy CA, et al (2006) Race, breast cancer subtypes, and survival in the Carolina Breast Cancer Study JAMA: J Am Med Assoc 2950(21) 2492-502 https://doi.org/10.1001/jama.295.21.2492

37. Singer R, Henke A, and Alloyce JP, et al (2021) Repetitive cancer training for community healthcare workers: an effective method to strengthen knowledge and impact on the communities: results from a pilot training at Kilimanjaro Region, Tanzania J Cancer Educ 36(3) 470-477. https://doi.org/10.1007/s13187-019-01648-6

38. Amadori D, Serra P, and Bravaccini S, et al (2014) Differences in biological features of breast cancer between Caucasian (Italian) and African (Tanzanian) populations Breast Cancer Res Treat 145(1) 177-183 https://doi.org/10.1007/s10549-014-2903-0 PMID: 24658893

39. Meijer SL, Wesseling J, and Smit VT, et al (2011) HER2 gene amplification in patients with breast cancer with equivocal IHC results J Clin Pathol 64(12) 1069-1072. https://doi.org/10.1136/jclinpath-2011-200019 PMID: 21836036

40. Roy I, and Othieno E Breast carcinoma in Uganda: microscopic study and receptor profile of 45 cases Arch Pathol Lab Med 135(2) 194-199 PMID: 21284437

41. Zuo T, Zeng H, and $\mathrm{Li} \mathrm{H}$, et al (2017) The influence of stage at diagnosis and molecular subtype on breast cancer patient survival: a hospital-based multi-center study Chin J Cancer 36(1) 84 https://doi.org/10.1186/s40880-017-0250-3 PMID: 29070080 PMCID: 5657106 
42. Dodiya H, Patel A, and Patel D, et al (2013) Study of hormone receptors and epidermal growth factor expression in invasive breast cancers in a cohort of Western India Indian J Clin Biochem 28(4) 403-409. https://doi.org/10.1007/s12291-012-0294-8 PMCID: 3783920

43. Howlader N, Chen VW, and Ries LA, et al Overview of breast cancer collaborative stage data items-their definitions, quality, usage, and clinical implications: a review of SEER data for 2004-2010 Cancer 120 3771-3780

44. Mremi A, Broadwater G, and Jackson K, et al (2019) Breast cancer in Tanzanian, black American, and white American women: an assessment of prognostic and predictive features, including tumor infiltrating lymphocytes PLoS One 14(11) e0224760 https://doi. org/10.1371/journal.pone.0224760 PMID: 31703083 PMCID: 6839867

45. Stuart-Harris R, Caldas C, and Pinder SE, et al (2008) Proliferation markers and survival in early breast cancer: a systematic review and meta-analysis of 85 studies in 32,825 patients Breast 17(4) 323-34 https://doi.org/10.1016/j.breast.2008.02.002 PMID: 18455396

46. Kurozumi S, Matsumoto $\mathrm{H}$, and Kurosumi $\mathrm{M}$, et al (2019) Prognostic significance of tumour-infiltrating lymphocytes for oestrogen receptor-negative breast cancer without lymph node metastasis Oncol Lett 17(3) 2647-2656 https://doi.org/10.3892/ol.2019.9938 PMID: 30867728 PMCID: 6396218

47. Botteri E, Veronesi $\mathrm{P}$, and Vila J, et al (2017) Improved prognosis of young patients with breast cancer undergoing breast conserving surgery BrJ Surg 104(13) 1802-1810 https://doi.org/10.1002/bjs.10658 PMID: 28791694

48. Galukande M, Wabinga H, and Mirembe F (2015) Breast cancer survival experiences at a tertiary hospital in sub-Saharan Africa: a cohort study World J Surg Oncol 13(1) 220 https://doi.org/10.1186/s12957-015-0632-4 PMID: 26187151 PMCID: 4506617

49. Walters S, Maringe C, and Butler J, et al (2013) Breast cancer survival and stage at diagnosis in Australia, Canada, Denmark, Norway, Sweden and the UK, 2000-2007: a population-based study Br J Cancer 108(5) 1195 https://doi.org/10.1038/bjc.2013.6 PMID: 23449362 PMCID: 3619080

50. Yang K, Msami K, and Calixte R, et al (2019) Educational opportunities for down-staging breast cancer in low-income countries: an example from Tanzania J Cancer Educ 34 1225-1230 https://doi.org/10.1007/s13187-019-01587-2 PMID: 31435911

51. Malone KE, Daling JR, and Doody DR, et al (2011) Family history of breast cancer in relation to tumor characteristics and mortality in a population-based study of young women with invasive breast cancer Cancer Epidemiol Prev Biomarkers 20(12) 2560-2571 https://doi. org/10.1158/1055-9965.EPI-11-0781 